\title{
Potential for shale gas of the Pimenteiras Formation in the Central Portion of the Parnaíba Basin
}

Julia Pires de Oliveira Machado¹, Antônio Fernando Menezes Freire ${ }^{1}$

1 Universidade Federal Fluminense

Copyright 2021, SBGf - Sociedade Brasileira de Geofísica

This paper was prepared for presentation during the $17^{\text {th }}$ International Congress of the Brazilian Geophysical Society held in Rio de Janeiro, Brazil, 16-19 August 2021.

Contents of this paper were reviewed by the Technical Committee of the $17^{\text {th }}$ International Congress of the Brazilian Geophysical Society and do not necessarily represent any position of the SBGf, its officers or members. Electronic reproduction or represent any position of the SBGf, its officers or members. Electronic reproduction of
storage of any part of this paper for commercial purposes without the written consent storage of any part of this paper for commercial pur
of the Brazilian Geophysical Society is prohibited.

\begin{abstract}
Parnaíba Basin is an intracratonic type sedimentary basin that occupies about $650,000 \mathrm{~km}^{2}$ of area and covers states in the North and Northeast of Brazil. The Devonian shales of the Pimenteiras Formation have a low depth of burial, thermal maturation associated with igneous intrusions and high levels of Total Organic Carbon (TOC) in certain regions of the basin, making it interesting for the study of this rock as an unconventional resource. We evaluated the potential of the Pimenteiras Formation as an unconventional gas reservoir, through the integration of geochemical data, geophysical well logs and drill cutting samples from two wells located at the Parque dos Gaviões area. Geochemical characterization was carried out regarding the quantity, quality and maturation of organic matter, provided by the E\&P Database Bank (BDEP) of the National Petroleum Agency (ANP). Gamma Ray (GR), Resistivity (RES) and Sonic (DT) curves were used to synthetically quantify the Total Organic Carbon (TOC) content using the $\Delta$ LogR technique, which was later compared with the TOC obtained in the laboratory. The X-Ray Fluorescence and X-Ray Diffraction data were used for the mineralogical and chemical analysis, which is one of the necessary factors to enable the evaluation of unconventional shale gas reservoirs. The study made it possible to characterize the shales of the Pimenteiras Formation in the studied wells as good TOC content. However, this interval is immature and appears to be saturated with gas, probably migrated from intervals where generation occurred by contact with diabase sills. In this way, it is possible to consider the range of Pimenteiras Fm., in these wells, as being a naturally fractured shale, carrying gas.
\end{abstract}

\section{Introduction}

The growing demand for energy, the progress of new technologies in the oil industry and the large number of reserves in the world has been making the exploration of unconventional petroleum resources viable, such as shale oil and shale gas. These resources are different from conventional ones in that they are independent systems, where generation, reserve and trapping occur in a single rock. The exploration of these sources has become commercially interesting in the United States with the development of hydraulic fracturing and horizontal well drilling techniques.

In this context, it is strategic to identify and characterize basins that potentially produce unconventional resources in Brazil. RODRIGUES (1995) identified that the shales of Pimenteiras Formation present good values of Total Organic Carbon (TOC), varying between 2 and $6 \%$, and organic matter of types II and III, but with low economic interest due to the low depth of burial for thermal maturation. However, diabase intrusions were responsible for the thermal maturation of the gas system present in the basin. Furthermore, MIRANDA (2014) evaluated the shales of Pimenteiras Fm., like a potential unconventional reservoir of shale gas type. As an exploratory frontier is still classified, the Parnaíba Basin needs further studies regarding its exploration potential.

This work aims to evaluate the unconventional potential of the shale gas type of Pimenteiras Fm. from the integration of geochemical, geological and geophysical data, further to assessing the viability of exploration (hydraulic fracturing) from the analysis of the brittleness of rocks in this formation, present in the Parque dos Gaviões area.

\section{Method}

The objects of this study are data from wells OGX-77 and OGX-110 provided by ANP (Figure 1). The first well was chosen because it is the only one available with information on organic geochemistry and mineralogy obtained in the laboratory.

Well OGX-110 was selected because it reaches the depth of the Pimenteiras Fm. and has cuttings available. However, this well does not have available geochemical information, and for this reason, data from well OGX-77 were used for correlation between the 2 wells, depths transformed into quotas and corrected in relation to the rotating table (TVDSS).

The logs from both wells were used to apply the indirect $\Delta \mathrm{Log} R$ method and later compare it with the data obtained in the laboratory. 


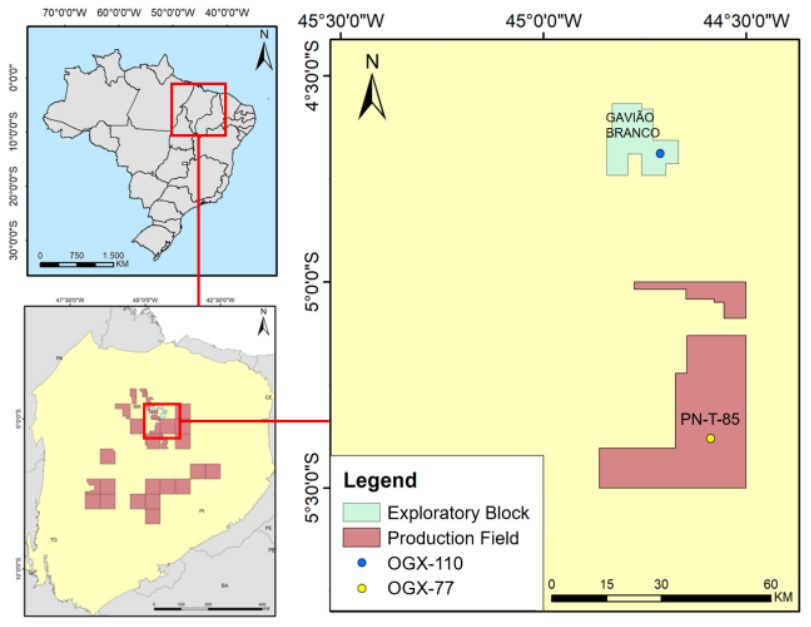

Figure 1: Location of wells $\mathrm{OGX}-110$ in the Gavião Branco field and OGX-77 in the exploratory block PN-T85.

\section{Geochemical Characterization}

Total Organic Carbon (COT) and Rock-Eval Pyrolysis geochemical data from 8 samples of the Pimenteiras Formation from well OGX-77 were used for geochemical characterization based on the quantity and quality of organic matter, in addition to the thermal maturation. The values are described and interpreted according to the bibliography of TISSOT \& WELTE (1984) and PETERS \& CASSA (1994). Furthermore, scatter plots were used to better interpret the data.

\section{$\Delta \log R$ Tecnique}

The $\Delta$ LogR method proposed by Passey et al. (1990) aims to estimate COT through well logs and was applied in this work based on an algorithm developed in the Python programming language by Santos and Freire (2017) at Universidade Federal Fluminense. This script receives input data from the caliper, gamma, resistivity and sonic logs, plus COT data, obtained in the laboratory, for comparison.

The script generates a graphical interface where it is possible to define the interval of interest, the baselines and the Level of Mature (LOM) value that is established from the Vitrinite Reflectance data.

\section{Brittleness}

For brittleness analysis, a different methodology was used for each well. In the OGX-77, a ternary diagram was plotted based on the percentages of minerals obtained through the XRD technique that were provided by the ANP. The $z$ axis represents the sum of concentrations of quartz, feldspar and pyrite, while the $y$ axis represents the sum of concentrations of clay minerals and the $x$ axis, the sum of concentrations of carbonates.

In the well OGX-110, due to the lack of information on the quantities of each mineral, a method proposed by Atar et. al. (2019) based on XRF data. In this technique, a ternary diagram was also plotted, but each axis with chemical elements more present in each large group of minerals:

- $\mathrm{SiO}_{2}$ oxide was used to represent quartz;

- $\mathrm{CaO}+\mathrm{MgO}$ were used for carbonates;

- Clay minerals were represented by the sum of the oxides $\mathrm{Al}_{2} \mathrm{O}_{3}, \mathrm{~K}_{2} \mathrm{O}, \mathrm{ThO}_{2}$ with the trace element $\mathrm{U}$.

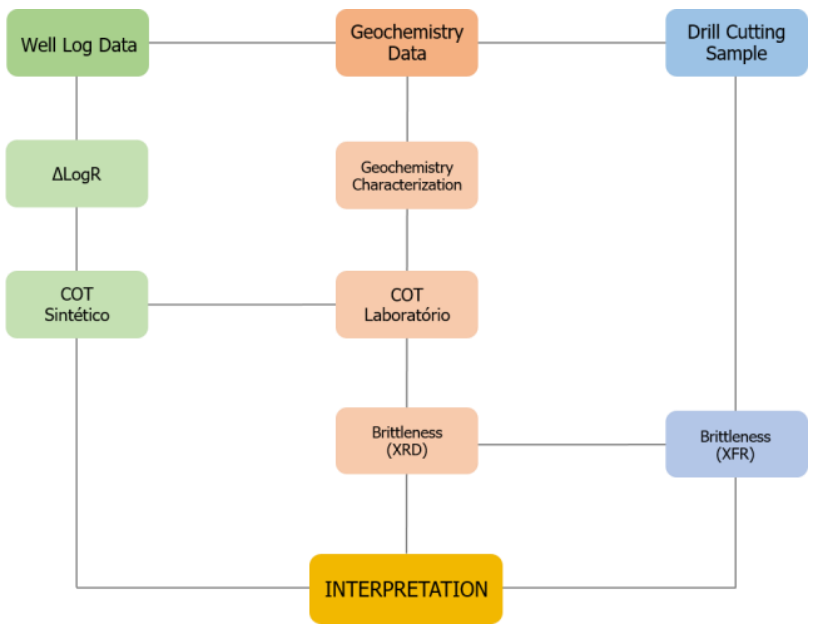

Figure 2: Methodology workflow.

\section{Results and Discussion}

\section{Geochemical Characterization}

The results of the parameters obtained by the TOC and Rock-Eval Pyrolysis analysis for well OGX-77 are summarized in Table 1. The content of TOC ranges from $0.08 \%$ to $2.48 \%$. The potential for hydrocarbon generation is considered poor in samples G1 and G2, good in samples $\mathrm{G} 2$ to $\mathrm{G} 7$ and has very good potential in sample G8. This interpretation is corroborated by TISSOT \& WELTE (1984), who state that a potentially generating shale has a minimum TOC of $1 \%$.

Table 1: Organic geochemical data from well OGX-77.

\begin{tabular}{|c|c|c|c|c|c|c|c|c|c|c|c|}
\hline Sample & Depth (m) & TOC (\%) & $\mathrm{S} 1(\mathrm{mg} / \mathrm{g})$ & $\mathrm{S} 2(\mathrm{mg} / \mathrm{g})$ & $\mathrm{S} 3(\mathrm{mg} / \mathrm{g})$ & $T \max \left({ }^{\circ} \mathrm{C}\right)$ & $\mathrm{HI}$ & Ol & $\mathrm{s} 2 / \mathrm{s} 3$ & PI & Ro (\%) \\
\hline G1 & 1423.07 & 0.08 & 0.04 & 0.13 & 0.36 & 0 & 163 & 450 & 0.4 & 0.24 & \\
\hline G2 & 1802.0 & 0.26 & 2.19 & 0.5 & 0.73 & 427 & 192 & 281 & 0.7 & 0.81 & 0.53 \\
\hline G3 & 1804.0 & 1.27 & 0.74 & 0.16 & 0.27 & 0 & 13 & 21 & 0.6 & 0.82 & - \\
\hline G4 & 1806.0 & 1.61 & 0.6 & 0.2 & 0.23 & 0 & 12 & 14 & 0.9 & 0.75 & - \\
\hline G5 & 1808.0 & 1.1 & 0.61 & 0.18 & 0.22 & 0 & 16 & 20 & 0.8 & 0.77 & - \\
\hline G6 & 1941.5 & 1.86 & 1.41 & 0.3 & 0.26 & 371 & 16 & 14 & 1.2 & 0.82 & - \\
\hline G7 & 2002.4 & 1.72 & 1.77 & 0.36 & 0.45 & 404 & 21 & 26 & 0.8 & 0.83 & 0.11 \\
\hline G8 & 2032.1 & 2.48 & 3.18 & 0.34 & 0.73 & 382 & 14 & 29 & 0.5 & 0.90 & \\
\hline
\end{tabular}

On the basis of the Rock-Eval Pyrolysis, it is possible to identify the type of kerogen present in the samples. The data show S1 values ranging from 0.04 to $3.18 \mathrm{mg} \mathrm{HC} / \mathrm{g}$ rock, S2 ranging from 0.13 to $0.50 \mathrm{HC} / \mathrm{g}$ rock. The results of $\mathrm{IH}$ range from 12 to $192 \mathrm{mg} \mathrm{HC} / \mathrm{g}$ of TOC and the Productivity Index ranges from 0.24 to 0.90 . Particularly, the data from samples $\mathrm{G} 1$ and $\mathrm{G} 2$ are not reliable because the TOC is less than $1 \%$ and were discarded in the plots. 
The results of the 10 parameter in most samples are greater than those of $\mathrm{IH}$, which in turn has very low values linked to the S2 peak. This suggests that the organic matter was deposited in an environment that did not allow its preservation and that is why it was oxidized. Therefore, kerogen has a low generation potential. Figure 3 shows the Van Krevelen-type diagram that relates the information of Hydrogen Index and Oxygen Index.

It is possible to estimate the degree of thermal evolution of the samples based on peak of the potential generation (Tmax), Reflectance of Vitrinite (Ro) and Production Index (IP). The Ro indicator was only provided for two samples and since it is an optical parameter, it is possible to trust the value of point G2. The results, which are $0.53 \%$ (sample G2) and $0.11 \%$ (sample G7), show the kerogen is in the immature stage. This conclusion is corroborated by the Tmax indicator, which varies from $371^{\circ} \mathrm{C}$ to $427^{\circ} \mathrm{C}$ in the samples in which data are provided.

On the other hand, the IP data vary from 0.24 to 0.83 and suggest that the samples are supermature, confronting the information from Tmax and Ro. This discrepancy between the indicators of thermal maturation is possibly the result of contamination of the drilling fluid that is based on n-paraffins in the samples that affect the $\mathrm{IH}$ values.
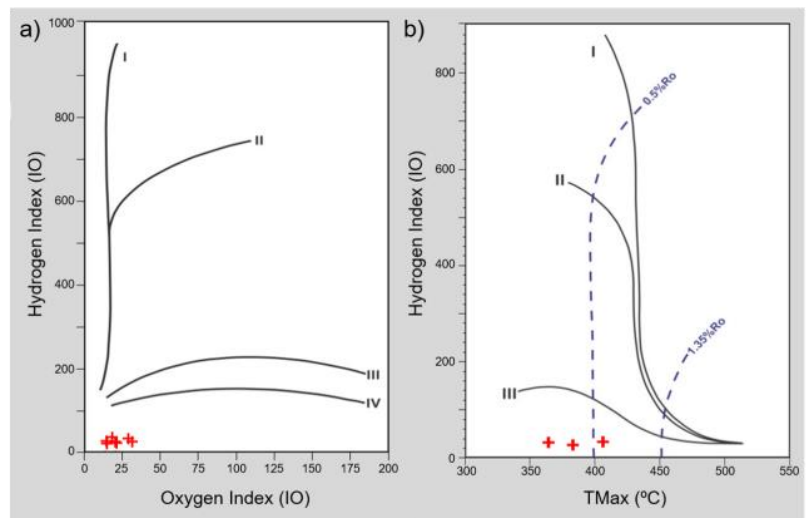

Figure 3: a) Van Krevelen-type diagram of the samples indicating type IV kerogen; b) Dispersion graph relating the Hydrogen Index $(\mathrm{IH})$ with the Tmax indicating a predominance of immature kerogen.

\section{$\Delta$ LogR Tecnique}

The $\Delta$ LogR plot for well OGX-77 is shown in Figure 4 with Pimenteiras Fm. highlighted. Usually, the baseline must be applied in some interval of fine granulometry and nongenerator level. However, the base that best adjusted the overlap between the resistivity and sonic curves was in the Poti Formation, which has shales interspersed between sandstones. The LOM was converted to 8 based on the Vitrinite Reflectance data.

It is observed that the values of the synthetic TOC extrapolate in many points to the laboratory values showing, consequently, a low calibration between the measured TOC and the calculated TOC.
It is important to highlight that, although the interval $1400 / 1600 \mathrm{~m}$ indicates the presence of igneous intrusions, they were not sufficient to thermally affect the shales of Pimenteiras Fm. in this interval, since geochemical data indicate that kerogen is immature.

Moreover, the behavior of the resistivity curve in the depth of the Pimenteiras Formation indicates that there is probably a presence of gas dispersed in shales. Analyzing the sonic curve, it can be inferred that its peaks in the $1950 / 2015 \mathrm{~m}$ interval are due to possible fractures, with the gas contained in them causing an increase in transit time. As the kinematic indicators Ro and Tmax indicate that the kerogen is not in the generation window, it is concluded that the hydrocarbon present in this shale came migrated from another interval, which mischaracterizes the possibility of being an unconventional reservoir of shale gas type. The presence of gaseous hydrocarbons in the formation is corroborated by the gas shows informed in the composite logs.

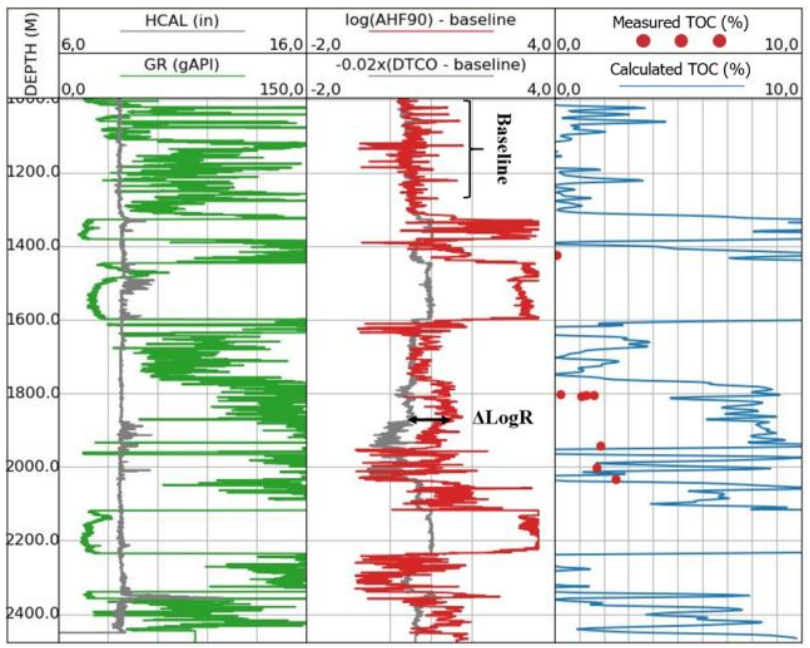

Figure 4: Result of the $\Delta$ LogR technique in the well OGX77. Note that the calculated TOC values are much higher than the COT values measured in the laboratory.

\section{OGX-110}

As this well does not have geochemical data, laboratory TOC and thermal maturation information was brought from well OGX-77, by a correlation. Due to the considerable distance between wells $(>60 \mathrm{~km})$, the technique was tested for the scenarios of non-maturation and thermal maturation levels.

In the same way as well OGX-77, it was not possible to find a good calibration between the calculated TOC and the measured TOC, considering the immature organic matter for gas generation $(\mathrm{LOM}=8)$. However, for a scenario in which the kerogen is mature $(\mathrm{LOM}=10)$ the data calibrates better, and it should also be considered that the drill cutting samples have a delay in the return time, requiring a vertical correlation between the depths of the drilling and the logs. The results are plotted in Figures $4(\mathrm{LOM}=8)$ and $5(\mathrm{LOM}=10)$. 
Regarding well OGX-110, the baseline was chosen for the shales interspersed in the Cabeças Formation. The correlation between the synthetic TOC curve with the laboratory data was made with well OGX-77. Furthermore, two LOM values were tested to see in which case the curve would fit better: 8 for an immature scenario and 10 considering the mature kerogen.

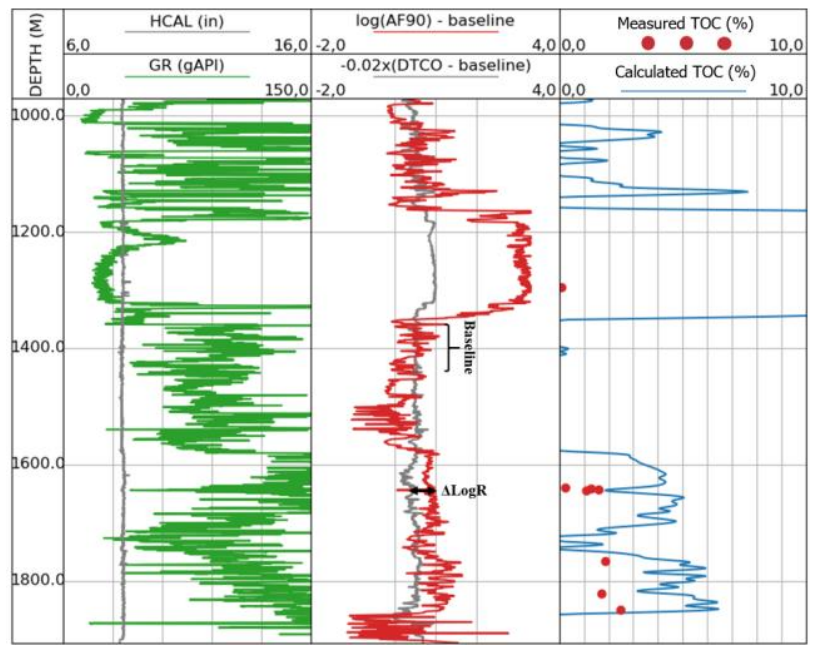

Figure 5: Result of the $\Delta \mathrm{LogR}$ technique in well OGX-110 considering LOM $=8$ (immature).

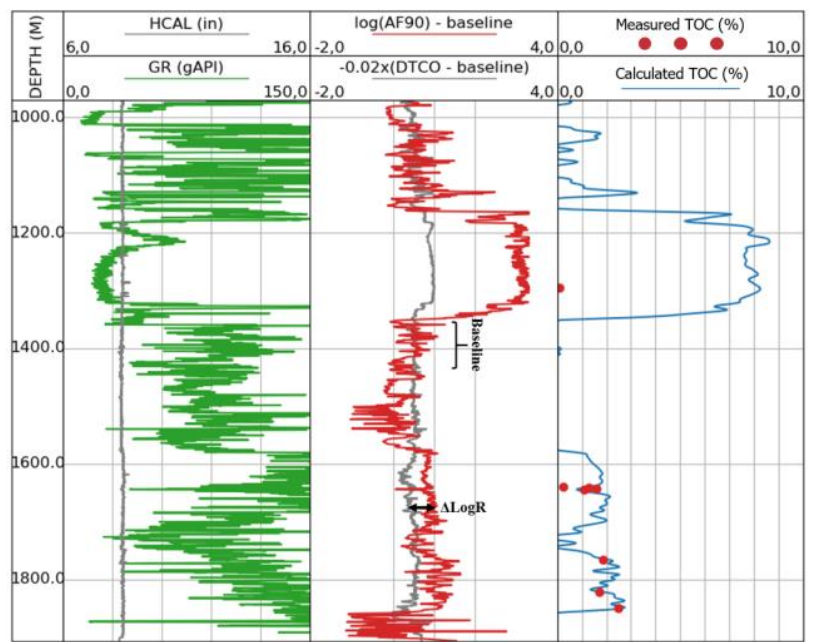

Figure 6: Result of the $\Delta$ LogR technique in well OGX-110 considering LOM $=10$ (mature).

\section{Brittleness}

Brittleness is one of the most important factors in the evaluation of a shale gas reservoir. The ability of the shale to be fractured increases towards the bottom of the ternary diagram. In well OGX-77, there is a predominance of clay minerals that make the rock more ductile and less susceptible to hydraulic fracturing (Figure 6a).

Well OGX-110, on the other hand, was analyzed based on the predominant chemical elements in each group of minerals. In this well, it is possible to identify a greater amount of silicate, which suggests the presence of quartz that can characterize a brittle behavior of the analyzed formation (Figure 6b). However, it is necessary to calibrate this technique with XRD data to validate this interpretation.

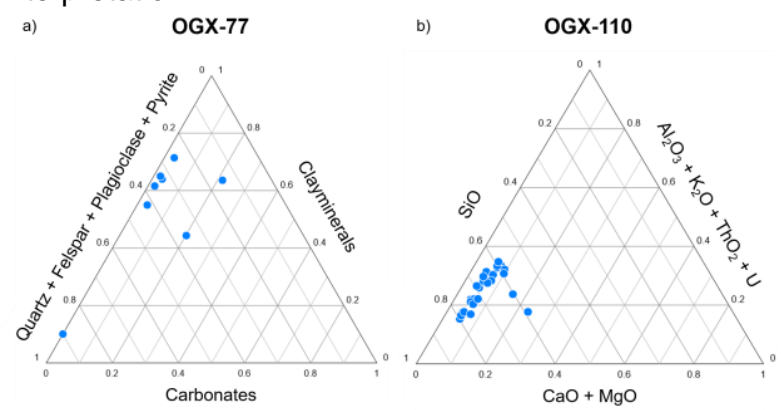

Figure 7: a) XRD data from well OGX-77 plotted on a ternary diagram and b) XRF data from well OGX-110 plotted on a ternary diagram.

\section{Conclusions}

Based on the geochemical interpretation of samples from well OGX-77, it was observed that the shales of Pimenteiras Fm. do not have hydrocarbon generation potential, since the organic matter is of type IV, that is, it suffered oxidation at the time deposition and is of poor quality. On the other hand, it was verified that possibly the samples were contaminated by drilling fluid that may have affected the results of the pyrolysis, but the immaturity of the kerogen is evidenced through the Vitrinite Reflectance data and, therefore, is not in the generation window. Regarding the $\Delta$ LogR technique, the result of well OGX77 proved to be overestimated due to the occurrence of migrated gas, affecting the resistivity and sonic values. However, the result of well OGX-110 had a good calibration considering mature kerogen. For a deeper analysis of this well, geochemical data would be needed to integrate the information, since the distance between the wells is considerably high. In addition, the presence of hydrocarbons in the Pimenteiras Formation, although there is no maturation for gas generation, shows that this content has migrated from other intervals, probably due to the thermal cracking generated by contact with igneous intrusions. Therefore, it is a fractured shale with the presence of hydrocarbon that has undergone secondary migration, and cannot be considered a shale gas reservoir, but a fractured gas reservoir. From the point of view of rupture, well OGX-77 does not have enough quartz and carbonate contents to provide the necessary rupture level for hydraulic fracturing. Despite this, well OGX-110, through analysis of chemical elements (XRF) presents interesting levels for fracturing. This discrepancy between the two wells may be due to the distance between the wells or to the different applied methodologies, requiring a calibration between the techniques, here being a recommendation for future studies.

\section{Acknowledgments}

I thank to BDEP/ANP and PGN for making the data available. To the companies $\mathrm{K} 2$ for allowing the use of 
Trace and Lloyd's Register software by Interactive Petrophysics software.

\section{References}

ATAR, E., MÄRZ, C., APLIN, A., DELLWIG, O., HERRINGSHAW, L., LAMOUREUXVAR, V., \& WAGNER, T. 2019. Dynamic climate-driven controls on the deposition of the Kimmeridge Clay Formation in the Cleveland Basin, Yorkshire, UK. Climate of the Past Discussions, 1-34.

MIRANDA, F. Pimenteiras Shale: Characterization of an atypical unconventional petroleum system, Parnaíba Basin, Brazil. Search and Discovery Article, 10369. 2014

PASSEY, Q. R.; CREANEY, S.; KULLA, J.B.; MORETTI, F.J., STROUD, J.D. Practical model for organic richness from porosity and resistivity logs. 1777-1794 p. 1990.

PETERS, K. E.; CASSA M. R. Applied source rock geochemistry. In: Magoon L.B. and Dow W.G. (Ed.), The Petroleum System - from Source to Trap. AAPG Memoir, v. 60, 93-120, 1994.

RODRIGUES, R. A Geoquímica Orgânica na Bacia do Parnaíba. Tese de D.Sc., Instituto de Geociências/Universidade Federal do Rio Grande do Sul, Porto Alegre, RS, Brasil. 1995.

SANTOS, F. V.; FREIRE, A.F.M.. Aplicação da Técnica Delta Log $R$ para estimativa de Carbono Orgânico Total (COT) utilizando perfis de poços da Bacia de Campos. [S.I.]. 2017.

TISSOT, B.P \& WELTE, D.H. Petroleum Formation and Occurrence. Second Revised and Enlarged Edition. Berlin Heidelberg New York Tokyo. 1984. 